\title{
The Emotional Content of Faces Interferes with Inhibitory Processing: An Event Related Potential Study
}

\author{
Julieta Ramos-Loyo ${ }^{1}$, Andrés A. González-Garrido ${ }^{1}$, Gregorio García-Aguilar ${ }^{1} \&$ Yolanda Del Río-Portilla ${ }^{2}$ \\ ${ }^{1}$ Instituto de Neurociencias, Universidad de Guadalajara, Guadalajara, México \\ ${ }^{2}$ Facultad de Psicología, Universidad Nacional Autónoma de México, México \\ Correspondence: Julieta Ramos-Loyo, Instituto de Neurociencias, Universidad de Guadalajara, Guadalajara, \\ 44520, México. Tel: 52-333-777-1150 Ext.33354. E-mail: jramos@cencar.udg.mx
}

Received: March 21, 2013 Accepted: April 18, $2013 \quad$ Online Published: May 14, 2013

doi:10.5539/ijps.v5n2p52 URL: http://dx.doi.org/10.5539/ijps.v5n2p52

\begin{abstract}
Emotional stimuli interfere with other kinds of stimuli processing because they capture attentional resources in accordance with their adaptive importance. This suggests that it would be more difficult to inhibit emotional faces than neutral ones or objects. The present study evaluates the effects of facial emotional expressions on inhibitory processing using event-related brain potentials in a Go/NoGo paradigm. Event-related potentials were obtained in healthy subjects during emotional inhibition tasks involving anger and happiness, compared to non-emotional tasks based on simple objects and gender. Emotional tasks exhibited poorer performance than non-emotional ones. P3 latencies were longer during response inhibition to emotional faces than those obtained while inhibiting non-emotional stimuli. This study provides evidence that facial emotional content interferes with response inhibition since it may elicit additional neural resource demands.
\end{abstract}

Keywords: emotion, inhibition, N2-P3, ERP, Go/NoGo

\section{Introduction}

Every day, people are embedded in social relationships where recognizing facial emotional expressions is crucial for understanding the reactions and intentions of others. In this context, the human brain has developed mechanisms to identify emotional faces more quickly and accurately than other types of objects (Ro, Russell, \& Lavie, 2001). However, emotional recognition is not the only important factor, as cognitive regulation of the response to others' emotional expressions is also necessary to generate appropriate decisions that lead to adaptive behavior.

Several studies have dealt with the influence of affective stimuli on cognitive processes such as attention, memory, executive functions and creative thinking (e.g., Banich, Mackiewicz et al., 2009; Delplanque,_ Lavoie, et al., 2004; Fenske \& Eastwood, 2003; Finucane, 2011; Jaeger \& Rugg, 2012; Lindström \& Bohlin, 2012; Hoffstetter, Achaibou, \& Vuilleumier, 2012; Pessoa, 2009; Pessoa, Padmala, et al., 2012; Phelps, 2006; Pourtois, Schettino, \& Vuilleumier, in press; Sakaki \& Niki, 2011; Sakaki, Niki, \& Mather, 2012; Steidl, Razik, \& Anderson, 2011; Vanlessen, Rossi, et al., 2013). Emotional stimuli interfere with other kinds of stimuli processing because they divert attentional resources due to their adaptive importance (Ledoux, 1996; Vuilleumier, Armony, et al., 2001).

Inhibition is a primary cognitive ability of executive functions and behavioral regulation that is relevant to both cognitive and emotional issues (Barkley, 2001; Bjorklund \& Kipp, 2002; Ochsner \& Gross, 2005). Using a stop-signal paradigm, Verbruggen and De Houwer (2007) found that the level of arousal portrayed in emotional pictures is more important in inhibitory processing than their valence. They suggest that emotional stimuli interrupt ongoing cognitively-controlled activities by diverting attention from them. Some studies examining the effect of emotional valence using emotional pictures have reported that negative images produce more interference than positive ones (e.g., Delplanque et al., 2004; Hartikainen, Ogawa \& Knight, 2000; Tipples \& Sharma, 2000). Thus, it is clear that emotions have an important effect on cognitive processes, including inhibition which is the main focus of the present study.

One of the most common strategies used to evaluate inhibitory processes involves inhibiting the prepotent response in a Go/NoGo paradigm. A high rate of presentation of a frequent stimulus (Go) to which the subject 
must respond induces the establishment of a prepotent response, while a low rate of an infrequent stimulus (NoGo) in which subjects must withhold their responses, makes it possible to evaluate inhibitory abilities (Aron, Robbins, \& Poldrack, 2004).

Temporal activation of the neural substrates involved in inhibiting prepotent responses during Go/NoGo tasks have been studied using the brain event related potentials (ERP) technique, due to its high temporal resolution. The main ERP components associated with inhibition seem to be N2 and P3. N2 is a frontocentral negative deflection that commonly peaks between 200 and $400 \mathrm{~ms}$ after the stimulus. Its amplitude is higher in NoGo than in Go trials, and it has been suggested that it reflects inhibition processes related to frontal cortex functioning (Bokura, Yamaguchi, \& Kobayashi, 2001). P3 is a positive deflection with a maximum peak between 300 and 600 ms after the stimulus. It also shows higher amplitudes in NoGo than Go trials in the frontocentral regions; whereas in centroparietal areas a reverse pattern occurs that has also been implicated in inhibitory processes (Smith, Johnston, \& Barry, 2008).

A study conducted by Yu, Yuan and Luo (2009) using auditory emotional stimuli in a Go/NoGo design found an interferent effect of emotional stimuli on ERP components associated with inhibition. Specifically, the N2 component showed reduced amplitudes in NoGo trials only when emotional sounds were processed. In a visual Go/NoGo paradigm, Albert, López-Martin and Carretié (2010) examined the effect of neutral, positive and negative emotional contexts on a response inhibition task that used letters as stimuli. They found that the NoGo-P3 frontocentral amplitude was larger in the positive context than in the negative one, and was related to ACC activation. These results support the idea of an emotional valence effect on cognition.

On the other hand, the emotional valence effect could be enhanced when it occurs in a setting of naturally significant stimuli, such as faces. Emotion expressed in a face captures attention even when it is irrelevant to the task (Hodsoll, Viding, \& Lavie 2011). It is widely accepted that enhanced attention to emotional faces allows people to adapt their behavior so as to produce a more suitable response. Logically, then, it would be more difficult to inhibit responses to an emotional face than a non-emotional one, and emotions might exert a modulating effect on inhibitory processes. In particular, emotional expressions that have greater relevance for adaptation, such as anger depicts attentional superiority (Calvo, Avero, \& Lundqvist, 2006; Pinkham, Griffin, Baron, Sasson, \& Gur, 2010), and even not being consciously perceived can cause an affective reaction leading to a more negative evaluations of neutral novel objects (Almeida, Pajtas, et al., 2013). Therefore, threat related emotions could be more difficult to inhibit than happy or neutral expressions. In this regard, Schupp et al. (2004) found a facilitation effect in perceptual processing of threatening faces compared with nonthreatening neutral or friendly expressions, both in ERPs associated to early perceptual stimulus processing (early posterior negativity) and to later processing stages (late positive potentials). In the case of ERP the modulating effect of emotions could also be observed on late components traditionally linked to inhibitory mechanisms (N2-P3) or even on earlier waveforms associated with face recognition (vertex positive potential, VPP). VPP is recorded primarily at frontocentral sites between 140 and $180 \mathrm{~ms}$ after face presentation in relation to the face structural encoding stage that precedes the processing of emotional recognition (Jeffreys, 1996; Joyce \& Rossion, 2005; Rossion et al., 1999; Yuan, Guan, et al., 2011). Differences between emotions and neutral faces (Luo, Feng, et al., 2010), and among different emotions (Williams, Palmer, et al., 2006) have been found in VPP amplitudes.

Recently, Zhang \& Lu (2012) performed a Go/NoGo paradigm with facial emotional stimuli. In this study, subjects had to respond to gender in faces with a neutral expression or that depicted happy or fearful expressions, but not to the emotion itself. They found an increment in NoGo-P3 amplitudes in the emotional tasks, which they related to the attentional resources allocated to emotional faces.

Imaging studies have revealed the participation of different cortical regions in inhibitory processes specifically to facial emotional stimuli, using a Go/NoGo paradigm. Shafritz, Collins and Blumberg (2006) found greater activation in the VLPFC/anterior insula, posterior parietal cortex, ACC and left DLPFC during inhibition of happy and sad emotional faces. Similar results have been described by Hare et al. (2008) and Schulz et al. (2009) during inhibitory processes involving facial emotional expressions. In another FMRI study performed with happy and sad faces (Vanderhasselt, Kühn \& De Raedt, 2011), it has been found that high clinically healthy brooders, who frequently think about negative events, compensate for their difficulty in inhibiting negative information by recruiting more attentional control. This disengaging from the negative faces was correlated with more right DLPFC activation. Authors suggest that this mechanism might be based on an increased use of emotion regulation strategies.

Some studies have addressed the effects of emotional stimuli on inhibition processes using ERP in a Go/NoGo paradigm, regarding auditory emotional stimuli (Yu et al., 2009), visual letters within an emotional context 
(Albert et al., 2010), and gender in facial expressions (Zhang \& Lu, 2012). Also, the effects of emotions expressed by human faces on the inhibition of a prepotent response have been explored by imaging studies (Shafritz et al., 2006; Hare et al., 2008; Schulz et al., 2009); however, to the best of our knowledge, such effects have not been studied using ERP recordings that, as stated above, may explain the temporal occurrence of cognitive processes, and might serve as an index of the modulating effect of emotional stimuli on these processes, specifically inhibition. Therefore, the objective of the present study was to evaluate the effects of facial emotional expressions on inhibitory processing by evaluating ERPs in a Go/NoGo paradigm.

Based on the empirical evidence mentioned above we hypothesized that facial emotional expressions would impair the response inhibition to faces with emotional content -when compared to objects or neutral facesbecause they divert additional attentional resources due to their adaptive importance. This interference might be stronger when the faces shown express anger instead of happiness, due to the former's adaptive significance. Any such effect would be observable in both behavioral performance and the amplitude and latency of N2 and P3 ERP components while performing a Go/NoGo task.

\section{Method}

\subsection{Participants}

Sixteen healthy, young, right-handed males $(n=10)$ and females, with ages ranging from 21 to 35 years $(M=$ $25.43, S D=4.35)$ volunteered to participate in the study. All had attended regular schools for 16 to 19 years ( $M$ $=17.31, S D=1.25)$. Potential subjects with neurological or psychiatric antecedents, or who were undergoing medical treatment, or who were taking drugs were excluded from the sample. All subjects gave prior written consent to participate in the study after receiving a full explanation of the experimental procedures. The study was approved by the ethics committee of the Institute of Neuroscience.

\subsection{Stimuli and Experimental Procedures}

Subjects were seated in front of a computer screen at a distance of $60 \mathrm{~cm}$ and asked to perform four tasks that required them to inhibit the following: (1) non-facial stimuli (a specific object); (2) facial gender without emotional content (male faces); and, (3) two other facial emotional stimuli (anger, happiness) using a Go/NoGo task design. Two neutral emotional stimuli from the International Affective Picture System (IAPS, Lang, Bradley, $\&$ Cuthbert, 1997: numbers 7009 and 7233) were used for the non-facial task. Facial emotional expressions of 10 models (5 males and 5 females) with neutral expressions taken from Ekman and Friesen (1986) were used for the gender task, while 5 male faces were used for the happiness and anger tasks. The stimuli size was $12 \times 18 \mathrm{~cm}$ and the images appeared in the center of the screen against a black background.

All stimuli were presented sequentially in the center of the screen for $500 \mathrm{~ms}$ with an interstimulus interval of $1000 \mathrm{~ms}$. Each task consisted of 250 trials ( $70 \%$ Go, 30\% NoGo). Task presentation was counterbalanced across subjects and each trial block lasted approximately $6 \mathrm{~min}$. Participants were asked to respond as quickly and accurately as possible by pressing a key only during performance of the Go trials.

Figure 1 shows an example of the four tasks. In the case of the object task, subjects had to respond to the presentation of a cup (Go) but withhold responses when a plate appeared (NoGo). In the gender task, subjects had to respond to female faces but withhold responses to male ones. During the anger inhibition task, subjects responded to happy facial expressions, whereas during the happiness inhibition task, they were to respond only when a male portraying an angry expression appeared on the screen. All participants were trained before each task to assure that they had fully understood the instructions and were sufficiently well familiarized with the operations required.

The following behavioral variables were all recorded automatically by software for later analysis: number of correct responses; reaction times when Go trials were responded to correctly; and correct inhibitions. 


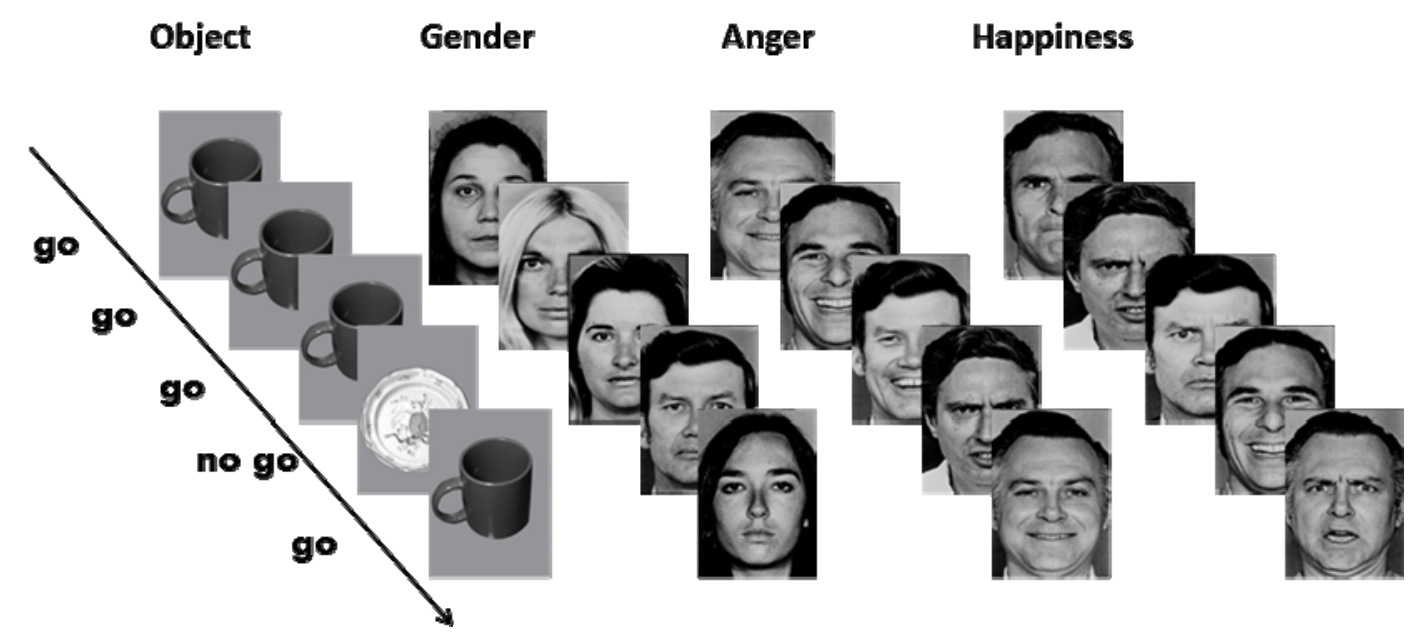

Figure 1. Go/NoGo task paradigm: Example of each task

\subsection{Electrophysiological Recording}

EEG was recorded continuously at Fp1, Fp2, F3, F4, F7, F8, T3, T4, T5, T6, P3, P4, O1, O2, Fz, Cz and Pz during task performance, according to the 10/20 International System, using linked earlobes as references with a digital Medicid 5 device (cut-off filters $.5-50 \mathrm{~Hz}$ ) at a sample rate of $250 \mathrm{~Hz}$. Electrode impedances were kept below $5 \mathrm{KOhms}$. Electro-oculogram (EOG) was also recorded bipolarly from electrodes placed bilaterally on the supraorbital and infraorbital eye regions in order to eliminate segments contaminated by eye movement artifacts. Twenty artifact-free epochs time-locked with the stimulus onset from the Go and NoGo signal trials were averaged independently to obtain the ERP components. These epochs corresponded exclusively to correct responses and were equal on the 4 tasks (object, gender, anger and happiness). Each epoch lasted $900 \mathrm{~ms}$ including the pre-stimulus time of $100 \mathrm{~ms}$ used to determine the baseline. The amplitude and latency values of each component peak were measured individually.

\subsection{Statistical Analysis}

Repeated-measure ANOVAs were performed to analyze behavioral performance using a one-factor design (Tasks: object, gender, anger and happiness) for each behavioral measure (correct responses, correct inhibitions and reaction times).

ERPs were first analyzed using 3 way RM-ANOVAs (Conditions: Go/NoGo; Tasks: object, gender, anger and happiness and; Electrode site: $\mathrm{Fz}, \mathrm{Cz}, \mathrm{Pz}$ ). Significance levels were established at $p<0.05$ and adjusted using the Greenhouse-Geisser epsilon correction. Therefore, corrected $p$ values are reported. Finally, post-hoc Tukey's $t$ tests and Bonferroni corrections for pairwise comparisons were conducted to adjust significance levels.

\section{Results}

\subsection{Behavioral Results}

Table 1 shows the behavioral values for each task. The percentage of correct inhibitions was significantly different among tasks $(F(3,45)=9.81, p<0.001)$ as it was higher for the objects than for anger and happiness $(p$ $<0.01)$ and higher for gender than both anger $(p<0.01)$ and happiness $(p<0.03)$. The reaction time analysis for correct responses also demonstrated a significant effect for tasks $(F(3,45)=4.40, p<0.01)$, with faster responses for gender than happiness $(p<0.004)$ in the Go trials. No differences were seen for correct responses during the Go trials. 
Table 1. Behavioral performance: Mean and standard deviation of the percentage of correct responses and correct inhibitions, as well as reaction times (ms) in each task

\begin{tabular}{cccc}
\hline & Go Correct Responses & NoGo Correct Inhibitions & Go Reaction Times \\
\hline Object & $95.27(7.47)$ & $88.20(7.89)$ & $321.57(53.91)$ \\
Gender & $96.04(8.92)$ & $87.39(9.47)$ & $309.57(35.06)$ \\
Anger & $89.82(10.45)$ & $80.14(10.26)$ & $330.62(49.01)$ \\
Happiness & $92.44(10.08)$ & $77.87(13.44)$ & $356.52(45.52)$ \\
\hline
\end{tabular}

\subsection{ERP Result}

Figure 2 illustrates the grand average ERP waveforms obtained during the tasks in every electrode site recorded. In Figure 3 the components obtained in the midline are labeled as follows: 1) N1 (90-150 ms) and 2) VPP (150-250 ms) mainly in the frontal and central regions; and, 3) N2 and P3 (200-350 ms and 350-550 ms, respectively) in the frontal, central and parietal regions. The latter two components were analyzed in relation to inhibitory mechanisms and the VPP to face-configuration processing. Time windows were determined on the basis of visual inspection of the main peaks in the group-averaged ERPs. Table 2 shows the amplitude and latency values obtained for each component during the four tasks for both the Go and NoGo conditions in the midline electrodes.

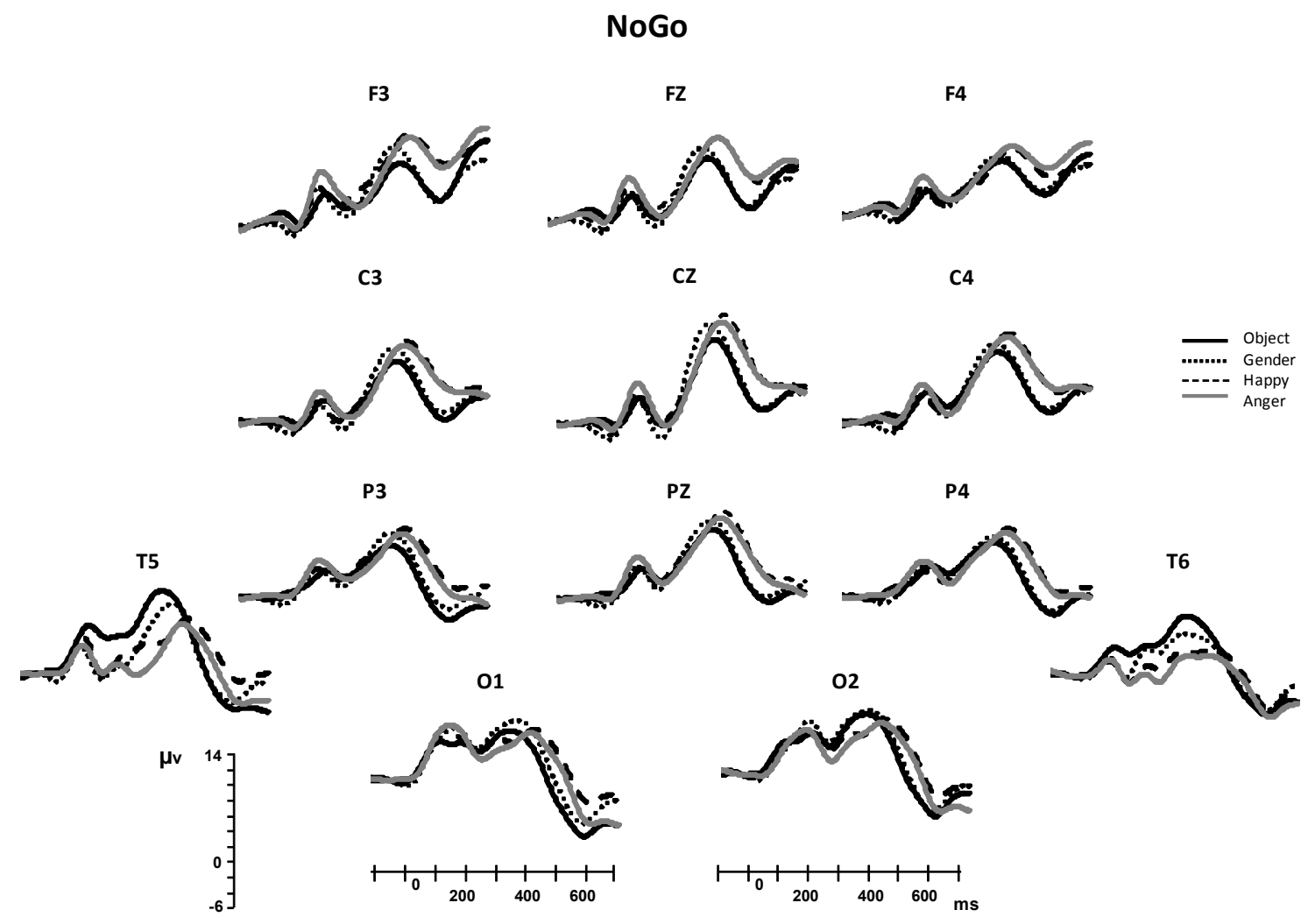

Figure 2. Grand averages of event-related potentials comparing the four tasks in the NoGo trials 


\subsubsection{Go/NoGo Differences}

Go and NoGo trials showed significant differences in VPP amplitude $(F(1,15)=6.16, p=0.025)$, with larger measures in the NoGo than the Go trials. Also, N2 and P3 amplitudes also showed higher values while processing the NoGo than the Go trials $(F(1,15)=24.25, p=0.001$, and $F(1,15)=35.23, p=0.001$, respectively). In addition, the NoGo condition revealed longer N2 and P3 latencies than the Go one $(F(1,15)=$ $19.70, p=0.001$, and $F(1,15)=82.49, p=0.001$, respectively). Figure 3 represents the waveform distributions in the Go and NoGo conditions in each of the experimental tasks.

\subsubsection{Topographic Distribution}

$\mathrm{N} 2$ and P3 amplitudes showed significant interactions of Conditions x Electrode sites $(F(1,15)=4.41, p=0.04$ and $(F(1,15)=22.97, p=0.001)$, respectively). N2 amplitude was larger in $\mathrm{Fz}$ than $\mathrm{Pz}(p<0.03)$ and in $\mathrm{Cz}$ than $\mathrm{Pz}(p<0.01)$ in the Go condition and; in $\mathrm{Cz}$ than $\mathrm{Fz}(p<0.03)$ and $\mathrm{Pz}(p<0.009)$ in the NoGo condition. P3 amplitudes were larger in $\mathrm{Cz}$ and $\mathrm{Pz}(p<0.002, p<0.01$, respectively) than $\mathrm{FZ}$ in the Go condition and; in $\mathrm{Cz}$ larger than $\mathrm{Fz}(p<0.001)$ and $\mathrm{Pz}(p<0.002)$ in the NoGo condition.

P3 latency also showed a significant interaction of Conditions $x$ Electrode sites $(F(2,30)=5.50, p=0.01)$ where shorter latency was seen in $\mathrm{Pz}$ than $\mathrm{Fz}(p<0.03)$ and $\mathrm{Cz}(p<0.01)$ only in the Go condition.

\subsubsection{Tasks Differences}

VPP component. The ANOVAs revealed significant differences among tasks in VPP amplitude $(F(3,45)=9.22$, $p<0.001)$ denoting that objects showed smaller amplitudes than anger $(p=0.02)$ and happiness $(p=0.001)$. In relation to VPP latency, significant differences were seen $(F(3,45)=56.29, p=0.001)$, where objects showed longer latencies than the facial tasks $(p=0.001)$.

N2 component. No significant differences were observed in N2 amplitude among tasks. Regarding to N2 latency, there were significant effects among tasks $(F(3,45)=7.50, p=0.001)$, as it was shorter for happiness than for objects $(p=0.01)$.

P3 component. Although P3 amplitude differences among tasks did not reach significant values, a tendency was observed $(F(3,45)=2.41, p=0.09)$. On the other hand, the ANOVAs that tested latency differences yielded significant effects for tasks $(F(3,45)=16.83, p<0.001)$, where P3 latency in the object task was shorter than in the anger $(p=0.004)$ and happiness tasks $(p=.006)$ and; in the gender task than in the anger $(p=0.001)$ and happiness tasks $(p=0.001)$. There were no significant interactions. 


\section{Frontal}

Go
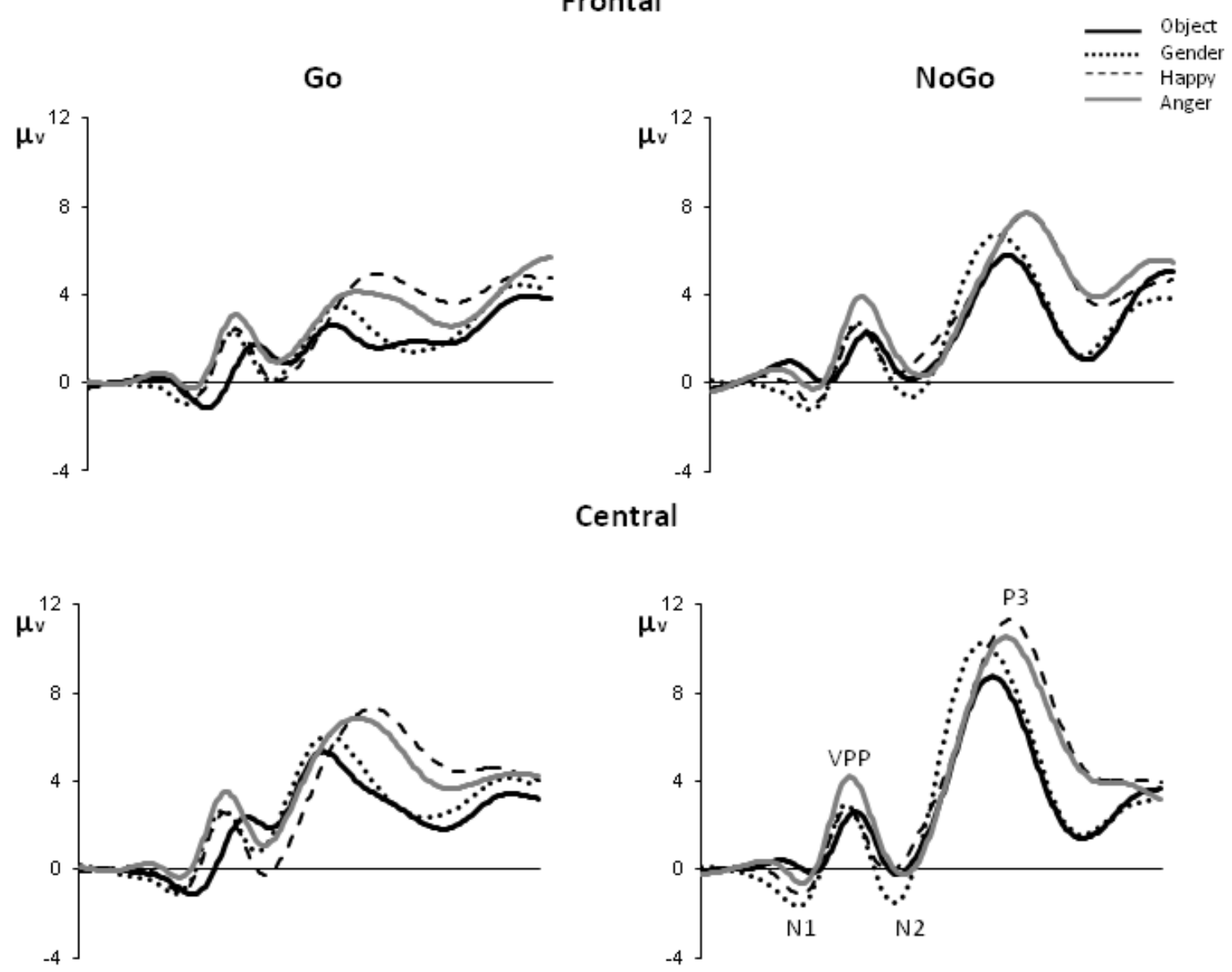

Parietal
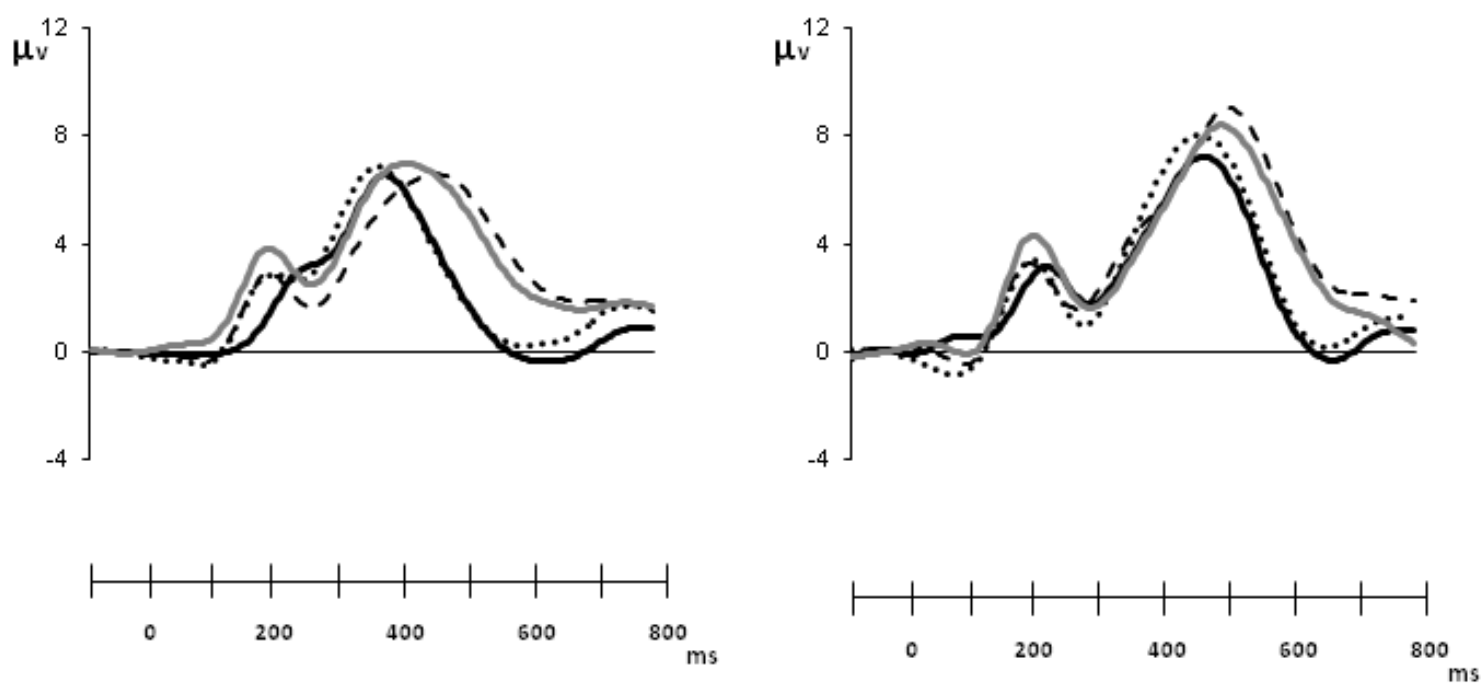

Figure 3. Grand averages of event-related potentials in the frontal (FZ), central (Cz) and parietal (Pz) regions, in Go and NoGo trials during the four tasks 
Table 2. Amplitude and latency values of ERP components for the trials in each task: Mean and standard deviation

\begin{tabular}{|c|c|c|c|c|c|c|c|c|}
\hline \multicolumn{9}{|c|}{ Amplitude } \\
\hline & \multicolumn{3}{|c|}{ Go } & & \multicolumn{4}{|c|}{ NoGo } \\
\hline & Object & Gender & Happiness & Anger & Object & Gender & Happiness & Anger \\
\hline \multicolumn{9}{|c|}{ VPP } \\
\hline $\mathbf{F z}$ & $3.38(2.6)$ & $6.66(2.1)$ & $7.40(3.0)$ & $6.63(2.4)$ & $4.01(4.0)$ & $6.91(2.9)$ & $6.91(3.3)$ & $7.95(2.8)$ \\
\hline $\mathrm{Cz}$ & $3.93(3.1)$ & $7.15(2.6)$ & $8.08(3.6)$ & $6.93(2.6)$ & $4.91(4.7)$ & $7.39(3.3)$ & $7.31(4.2)$ & $8.55(3.8)$ \\
\hline $\mathbf{P z}$ & $4.78(2.8)$ & $5.62(2.4)$ & $6.96(3.2)$ & $6.10(2.4)$ & $6.33(4.8)$ & $6.58(2.5)$ & $7.01(3.8)$ & $7.48(3.1)$ \\
\hline \multicolumn{9}{|l|}{ N2 } \\
\hline $\mathbf{F z}$ & $-1.25(2.3)$ & $-1.60(3.2)$ & $-1.16(2.4)$ & $-1.92(3.6)$ & $-2.52(4.1)$ & $-2.36(3.9)$ & $-1.77(3.4)$ & $-2.19(3.9)$ \\
\hline $\mathbf{C z}$ & $-.75(3.1)$ & $-1.02(3.9)$ & $-.99(2.7)$ & $-1.94(3.8)$ & $-3.78(4.7)$ & $-3.94(4.1)$ & $-2.11(4.4)$ & $-2.40(4.4)$ \\
\hline $\mathbf{P z}$ & $1.25(3.2)$ & $.44(3.6)$ & $.25(3.5)$ & $.18(3.1)$ & $-1.96(4.2)$ & $-1.90(2.9)$ & $-.38(3.9)$ & $-.31(3.6)$ \\
\hline \multicolumn{9}{|l|}{ P3 } \\
\hline $\mathbf{F z}$ & $5.24(3.0)$ & $5.63(3.8)$ & $8.87(2.0)$ & $6.18(3.9)$ & $8.37(4.2)$ & $9.99(4.1)$ & $9.95(3.2)$ & $10.75(3.9)$ \\
\hline $\mathbf{C z}$ & $7.82(5.2)$ & $8.58(5.1)$ & $8.98(3.7)$ & $8.92(4.5)$ & $12.09(5.4)$ & $13.49(5.8)$ & $13.64(5.3)$ & $13.82(6.5)$ \\
\hline $\mathbf{P z}$ & $8.46(4.8)$ & $8.87(5.6)$ & $9.06(3.6)$ & $8.22(4.3)$ & $10.09(4.8)$ & $10.57(4.6)$ & $11.21(4.7)$ & $11.18(5.1)$ \\
\hline \multicolumn{9}{|c|}{ Latency } \\
\hline \multicolumn{5}{|c|}{ Go } & \multicolumn{4}{|c|}{ NoGo } \\
\hline & Object & Gender & Happiness & Anger & Object & Gender & Happiness & Anger \\
\hline \multicolumn{9}{|c|}{ VPP } \\
\hline $\mathbf{F z}$ & $223(15.1)$ & 181(19.1) & $185(21.6)$ & $184(18.5)$ & $209(20.4)$ & $187(23.1)$ & $184(19.4)$ & $186(18.2)$ \\
\hline $\mathrm{Cz}$ & $226(11.3)$ & 181(19.0) & $184(20.1)$ & $184(17.1)$ & $209(16.6)$ & $189(23.9)$ & $183(18.4)$ & $185(17.7)$ \\
\hline $\mathbf{P z}$ & $229(24.6)$ & $174(19.0)$ & $176(16.9)$ & $184(17.4)$ & $221(15.3)$ & $178(22.4)$ & $187(36.3)$ & $188(22.1)$ \\
\hline \multicolumn{9}{|l|}{ N2 } \\
\hline $\mathbf{F z}$ & $285(21.1)$ & $267(39.8)$ & $255(31.5)$ & $270(40.6)$ & $292(48.3)$ & $287(44.6)$ & $273(55.0)$ & $307(44.9)$ \\
\hline $\mathbf{C z}$ & 281(16.4) & $257(39.8)$ & $259(29.1)$ & $272(43.5)$ & $295(37.7)$ & $287(37.9)$ & $267(45.2)$ & 293(43.1) \\
\hline $\mathbf{P z}$ & $269(31.1)$ & $241(40.4)$ & $245(30.0)$ & $256(35.2)$ & $297(38.5)$ & $273(40.2)$ & $270(52.9)$ & $302(51.6)$ \\
\hline \multicolumn{9}{|l|}{ P3 } \\
\hline $\mathbf{F z}$ & $423(74.0)$ & $415(49.0)$ & $430(51.7)$ & $453(38.8)$ & $478(33.7)$ & $461(44.8)$ & $508(51.2)$ & $502(41.0)$ \\
\hline $\mathrm{Cz}$ & $413(67.0)$ & $406(45.6)$ & $437(47.9)$ & $468(42.4)$ & $466(36.3)$ & $462(39.7)$ & $504(53.4)$ & $489(37.3)$ \\
\hline $\mathbf{P z}$ & $382(34.5)$ & $380(50.4)$ & $423(45.9)$ & $448(57.5)$ & $457(40.5)$ & $472(39.0)$ & $505(43.9)$ & $500(48.5)$ \\
\hline
\end{tabular}

\section{Discussion}

The aim of the present study was to evaluate the effects of facial emotional expressions on the inhibition of the prepotent response in a Go/NoGo paradigm. As was expected, faces portraying an emotion -anger or happinessresulted in poorer inhibition performance than images of objects, or faces with no emotional expression. Similarly, P3 latencies were longer during response inhibition to emotional faces (anger and happiness) than those obtained while inhibiting non-emotional stimuli (objects and gender).

ERP amplitudes showed clear differences between the Go and NoGo conditions. VPP, N2 and P3 amplitudes were larger during the inhibitory condition, while N2 and P3 latencies were longer in this condition. For N2 and P3, however, this difference depended upon regional distribution. During the Go conditions, N2 showed a frontocentral predominance while in the NoGo trials the larger amplitude was more evident in central regions.

In general, the magnitude of P3 amplitudes has been observed as larger and latency as longer in the NoGo compared to the Go condition over the frontocentral areas (Fallgrater \& Strik, 1999; Albert, et al., 2010; Chiu, 
Holmes, \& Pizzagalli, 2008; Gajewski \& Falkenstein, in press). The present results coincide with previous reports in which N2 has been related to cognitive control or response conflict (see Folstein \& Van Petten, 2008 for an extensive review) or the inhibition of a premature response plan (Gajewski \& Falkenstein, in press). Géczy, Czigler and Balázs (1999) point out that the increased N2 to NoGo stimuli following Go cues might be related to increased efforts to activate the response inhibition system thereby interrupting preparations to respond.

Also, the NoGo-P3 component has been interpreted as most likely linked to the inhibition of overt responses (Bruin \& Wijers, 2002) and to the efficiency of inhibitory control or the evaluation of the inhibition process (Liotti, Pliszka, et al., 2005; Schmajuk, Liotti, et al., 2006). In this regard, Bokura et al. (2001) found different generator sources for Go and NoGo P3, which may suggest distinct functional roles. While Go-P3 sources were found in the parietal lobe and the left superior prefrontal cortex, the main source of NoGo-P3 was located in the left lateral orbitofrontal cortex. This finding seems to reinforce the abovementioned notion that Go and NoGo-P3 may reflect distinct processes. Regarding the typical centroparietal distribution of $\mathrm{P} 3$, and in accordance with the nature of the present experimental tasks in the Go trials, the distribution expected -and found- for P3 in the Go trials matched that reported previously for $\mathrm{P} 3 \mathrm{~b}$ component related to the attentional processing of target stimulus events (see Polich, 2007 for review). Furthermore, during NoGo trials, P3 appeared enhanced mainly in central leads with longer latencies than in Go-P3, and thus corresponded to what it was expected for inhibitory related mechanisms in a Go/NoGo paradigm (Bokura et al., 2001).

The VPP has been related to a low-level stimulus stage of processing that responds preferentially to images of faces presented and to some common objects, though the latter only to a lesser extent. In addition, the VPP component is thought to be related to configurational face detection that precedes the processing stages of emotional recognition (Joyce \& Rossion, 2005; Rossion et al., 1999; Yuan et al., 2011). Although the VPP is largest over the midline frontocentral areas, its origin is probably located in bilateral sites of the inferotemporal cortex (for a review see Jeffreys, 1996). In the present work, we observed that those conditions which included facial stimuli showed significantly larger VPP amplitudes and shorter latencies than simple objects, both when subjects had to respond to targets (Go) and when they were instructed to withhold their responses (NoGo). This effect might depict the stimulus-driven recruitment of additional cognitive resources due to the intrinsic relevance of the facial stimuli, as has been suggested previously (Westerhausen et al., 2010). In contrast to other studies in which differences between emotions and neutral faces (Luo et al., 2010), or between different emotions (Williams et al., 2006), were observed with respect to VPP amplitudes, we found no relevant differences between neutral and emotional faces or between angry and happy ones; results that would seem to suggest a VPP association with configurational information processing more than with facial emotional processing. However, VPP also showed smaller amplitudes and longer latencies in non-facial than facial stimuli proving to be sensitive to the inhibitory demands of the task. This could open the possibility that VPP reveals more than just a simple stage in facial configuration encoding but actually reflects the cognitive resources engaged in this process, mainly attentional ones. In this case, VPP might increase its magnitudes with additional cognitive effort such as that required to deal with more complex and attractive stimuli including faces, especially emotional ones. Furthermore, the changes observed in VPP, together with other early face-sensitive components, could be used as markers to track the time course of face processing (Yuan et al., 2011), as well as the effects of emotional content within this time course.

On the other hand, facial emotional expressions also modulated late stimuli processing; given that behavioral results revealed that emotional stimuli interfered with inhibitory mechanisms, as demonstrated by the inhibition accuracy and longer reaction times. In addition, P3 amplitude showed a tendency to be higher and P3 latencies were longer during emotional tasks compared to non-emotional ones. An increase in latency was present in both the Go and NoGo trials; findings which may indicate that emotional stimuli require more time and additional processing resources in order to be recognized and categorized. In this regard, Mikhailova and Bogomolova (2000) found that the latencies of the N3 and P3 waves, which are associated with the later stages of information processing, increased when subjects were asked to recognize emotional facial expressions compared to those recorded during passive observation.

Although, P3 amplitude did not reach significant values between emotional stimuli and non-emotional ones a tendency can be observed, that may suggest that the emotional content of a face interferes with inhibitory processing and thus concord with those of Schulz et al. (2007) in Go/NoGo facial emotional tasks compared to non-emotional ones.

Similar results were reported by Yu et al. (2009), who found an interfering effect of emotional stimuli on ERP components associated with inhibition using auditory emotional stimuli, though the main effect they found was a reduction of $\mathrm{N} 2$ amplitude. Zhang and $\mathrm{Lu}$ (2012) performed a similar Go/NoGo paradigm to the one used in the 
present study; the only difference being that the emotional task was implicit; i.e., subjects had to respond to gender in faces with a neutral expression or ones that depicted happy or fearful expressions, but not to the emotion itself. They also found an increment in NoGo-P3 amplitudes in the emotional tasks, which they related to an automatic response inhibition in which the more attentional resources that were allocated to emotional faces, the greater the inhibition of the emotional response.

There is evidence to suggest that emotion naturally facilitates attention, mediated primarily by an arousal effect in which the main structure involved is the amygdala (for a review, see Phelps, 2006). However, other studies have found that emotion attracts attention, and thus impairs cognitive processing (Fenske \& Eastwood, 2003). Regarding the P3 latencies and the tendency of P3 amplitude to increase, our results may concord with the notion that affective stimuli capture attentional resources, and thus could affect not only the recognition and categorization of such phenomena, but also the inhibitory processing required to withhold responses.

It has been reported that facial emotional content acts not only as a recruiter of attentional resources but also promotes neural activity in additional areas to those related to the inhibition of letters, and that this can be modulated by emotional valence (Shafritz et al., 2006). This may indicate that P3 reflects those inhibitory processes influenced by the emotional significance of the stimuli and, therefore, reaches higher amplitudes in experimental tasks involving greater relevance; i.e., faces with emotional content. Also, P3 latencies were longer during inhibition of emotional faces than non-emotional and objects that may be related to a certain difficulty in the stimuli processing of this emotion. Therefore, these results could be related more to differences in the stimulus complexity, than to emotional content. This would mean that decisions based on facial emotions might require additional processing resources when compared to neutral faces; thus the comparison of non-emotional and emotional tasks could be biased by the physical complexity of differences among the stimuli. However, Gajewski and Falkenstein (in press) found that the amplitude of the NoGo-P3 decreased with rising task difficulty, instead of increasing, in a Go/NoGo task. In addition, it has been stated that the processing of anger expressions is more complex than that of happy faces (Kirouac \& Doré, 1984) though the present study found no behavioral differences nor electrophysiological differences between these two tasks, and thus casts doubt on the theoretical statement that higher complexity of facial emotions could be responsible for the differences in inhibition observed in non-emotional vs. emotional tasks.

Turning to stimuli relevance, one would expect that the effects of emotional content on inhibition would be greater for angry faces than for happy ones, due to the adaptive value of threats. An angry face can activate neural systems related to fear, especially the amygdala (Habel et al., 2007). Indeed, anger and fear may represent threatening events that must be identified and analyzed rapidly. As a result, one might expect that it would be more difficult to disentangle attention from anger than from happiness. However, observations have shown that happy faces are more efficiently detected than anger in visual search paradigms (Becker, Anderson, et al., 2011; Calvo \& Nummenmaa, 2008) and that response inhibition is more difficult with happy stimuli than negative ones (Schulz et al., 2007). In the present study, these two emotions induced similar processing effects in terms of both processing time and the resources involved.

The neural structures that participated in this effect of emotional faces on inhibitory processes cannot be described, as we did not conduct a source analysis or fMRI study. However, these effects may be related to the interaction of the two networks proposed by Schulz et al. (2009) during inhibition of responses to emotional faces: on the one hand, the frontoparietal circuit that exerts inhibitory control; and, on the other, the frontostriatal circuit, which is engaged in the decodification of emotional signals. Another point to be taken into account is the participation of the ACC in emotional valence, as has been described in other studies (Albert et al., 2010; Elliot, Rubitnsztein, et al., 2000). In this regard, Pessoa (2009) points out, hypothetically, that the anterior cingulate cortex is engaged in attentional/effortful control mechanisms and interaction with several other brain structures, including the amygdala and nucleus accumbens, in integrating affectively significant signals with control signals in the prefrontal cortex.

\section{Conclusion}

In conclusion, the current study provides evidence that face-emotional content interferes with response inhibition in a way that may be related to its social-adaptive importance. While an early face configurational component, VPP, is basically affected by facial informative complexity, P3 latency mainly in the No-Go trials were more sensitive to emotional significance than to gender or simple objects, thus making it more difficult to inhibit them. As present results suggest, the cognitive regulation of the response to others' emotional expressions goes beyond the simple perception, recognition and classification of affective stimuli to demand recruitment of additional neural resources; a finding that could explain the variations observed in both the ERP components and 
behavioral performance.

It would be interesting to apply this facial emotional Go/NoGo approach to groups that manifest behavioral alterations such as anxiety, impulsiveness and aggression; as well as in psychopathological populations such as schizophrenia and depression patients, where executive functions and/or emotional processes are known to be affected.

\section{References}

Albert, J., López-Martín, S., \& Carretié, L. (2010). Emotional context modulates response inhibition: Neural and behavioral data. Neuroimage, 49(1), 914-921. http://dx.doi.org/10.1016/j.neuroimage.2009.08.045

Almeida, J., Pajtas, P. E., Mahon, B. Z., Nakayama, K., \& Caramazza, A. (2013). Affect of the unconscious: Visually suppressed angry faces modulate our decisions. Cognitive, Affective, \& Behavioral Neuroscience, 13, 94-101. http://dx.doi.org/10.3758/s13415-012-0133-7

Aron, A. R., Robbins, T. W., \& Poldrack, R. A. (2004). Inhibition and the right inferior frontal cortex. Trends in Cognitive Sciences, 8(4), 171-177. http://dx.doi.org/10.1016/j.tics.2004.02.010

Banich M. T., Mackiewicz, K. L., Depue, B. E., Whitmer, A. J., Miller, G. A., \& Heller, W. (2009). Cognitive control mechanisms, emotion and memory: A neural perspective with implications for psychopathology. Neuroscience \& Biobehavioral Reviews, 33, 613-630. http://dx.doi.org/10.1016/j.neubiorev.2008.09.010

Barkley, R. A. (2001). The executive functions and self-regulation: An evolutionary neuropsychological perspective. Neuropsychological Review, 11(1), 1-29. http://dx.doi.org/1023/a:10090854177776

Becker, D. V., Anderson, U. S., Mortensen, C. R., Neufeld, S. L., \& Neel, R. (2011). The face in the crowd effect unconfounded: happy faces, not angry faces, are more efficiently detected in single- and multiple-target visual search tasks. Journal of Experimental Psychology: General. Advance online publication. http://dx.doi.org/10.1037/a0024060

Bjorklund, D. F., \& Kipp, K. (2002). Social cognition, inhibition, and theory of mind: The evolution of human intelligence. In R. J. Stenberg, \& J. C. Kaufman (Eds.), The evolution of intelligence (pp. 27-53). Mahnwah, NJ. Lawrence Erlbaum Associates.

Bokura, H., Yamaguchi, S., \& Kobayashi, S. (2001). Electrophysiological correlates for response inhibition in a $\begin{array}{lllll}\text { Go/NoGo task. } & \text { Clinical }\end{array}$ http://dx.doi.org/10.1016/S1388-2457(01)00691-5.

Bruin, K. J., \& Wijers, A. A. (2002). Inhibition, response mode, and stimulus probability: A comparative $\begin{array}{lllll}\text { event-related potential study. Clinical Neurophysiology, 113, 1172-1182. } & \text { 118 }\end{array}$ http://dx.doi.org/10.1016/S1388-2457(02)00141-4

Calvo, M. G., Avero, P., \& Lundqvist, D. (2006). Facilitated detection of angry faces: Initial orienting and processing efficiency. Cognition and Emotion, 20, 785-811. http://dx.doi.org/10.1080/02699930500465224.

Calvo, M. G., \& Nummenmaa, L. (2008). Detection of emotional faces: Salient physical features guide effective visual search. Journal of Experimental Psychology: General, 137(3), 471-494. http://dx.doi.org/10.1037/a0012771

Chiu, P. H., Holmes, A. J., \& Pizzagalli, D. A. (2008). Dissociable recruitment of rostral anterior cingulate and inferior frontal cortex in emotional response inhibition. NeuroImage, 42, 988-997. http://dx.doi.org/10.1016/j.neuroimage.2008.04.248

Delplanque, S., Lavoie, M. E., Hot, P., Silvert, L., \& Sequeira, H. (2004). Modulation of cognitive processing by emotional valence studied through event-related potentials in humans. Neuroscience Letters, 356, 1-4. http://dx.doi.org/10.1016/j.neulet.2003.10.014

Ekman, P., \& Friesen, W. V. (1986). Pictures of facial affect. Palo Alto: Consulting Psychologists Press.

Elliot, R., Rubitnsztein, J. S., Sahakian, B. J., \& Dolan, R. J. (2000). Selective attention to emotional stimuli attention to emotional stimuli in a verbal go/nogo task: An fMRI study. NeuroReport, 11, 1739-1744. Retrieved from http://www.ncbi.nlm.nih.gov/pubmed/10852235

Fallgatter, A. J., \& Strik, W. K. (1999). The NoGo-anteriorization as a neurophysiological standard-index for cognitive response control. International Journal of Psychophysiology, 32, 233-238. http://dx.doi.org/10.1093/cercor/bhs132

Fenske, M. J., \& Eastwood, J. D. (2003). Modulation of focused attention by faces expressing emotion: Evidence 
from flanker tasks. Emotion, 3(4), 327-343. http://dx.doi.org/10.1037/1528-3542.3.4.327

Finucane, A. M. (2011). The effect of fear and anger on selective attention. Emotion, 11(4), 970-974. http://dx.doi.org/10.1037/a0022574

Folstein, J. R., \& van Petten, C. (2008). Influence of cognitive control and mismatch on the N2 component of the ERP: a review. Psychophysiology, 45, 152-170. http://dx.doi.org/10.1111/j.1469-8986.2007.00602.x

Gajewski, P. D., \& Falkenstein, M. (2012). Effects of task complexity on ERP components in Go/Nogo tasks. International Journal of Psychophysiology, in press. http://dx.doi.org/10.1016/j.ijpsycho.2012.08.007

Géczy, I., Czigler, I., \& Balázs, L. (1999). Effects of cue information on response production and inhibition measured by event-related potentials. Acta Physiologica Hungarica, 86(1), 37-44. http://www.ncbi.nlm.nih.gov/pubmed/10755168.

Habel, U., Windischberger, C., Derntl, B., Robinson, S., Kryspin-Exner, I., Gur, R. C., \& Moser, E. (2007). Amygdala activation and facial expressions: Explicit emotion discrimination versus implicit emotion processing. Neuropsychologia, 45, 2369-2377. http://dx.doi.org/10.1016/j.neuropsychologia.2007.01.023

Hare, T. A., Tottenham, N., Galvan, A., Voss, H. U., Glover, G. H., \& Casey, B. J. (2008). Biological substrates of emotional reactivity and regulation in adolescence during an emotional go-nogo task. Biological Psychiatry, 63(10), 927-934. http://dx.doi.org/10.1016/j.biopsych.2008.03.015015

Hartikainen, K. M., Ogawa, K. H., \& Knight, R. T. (2000). Transient interference of right hemispheric function due to automatic emotional processing. Neuropsychologia, 38(12), 1576-1580. http://dx.doi.org/10.1016/S0028-3932(00)00072-5

Hodsoll, S., Viding, E., \& Lavie, N. (2011). Attentional capture by irrelevant emotional distractor faces. Emotion, 11(2), 346-353. http://dx.doi.org/10.1037/a0022771

Hoffstetter, Ch., Achaibou, C., \& Vuilleumier, P. (2012). Reactivation of visual cortex during memory retrieval: Content specificity and emotional modulation. Neuroimage, 60, 1734-1745. http://dx.doi.org/10.1016/j.neuroimage.2012.01.110

Jaeger, A., \& Rugg, M. D. (2012). Implicit effects of emotional contexts: An ERP study. Cognitive, Affective, \& Behavioral Neuroscience, 12, 748-760. http://dx.doi.org/10.3758/s13415-012-0110-1

Jeffreys, D. A. (1996). Evoked potential studies of face and object processing. Visual Cognition, 3(1), 1-38. http://dx.doi.org/10.1080/713756729

Joyce, C., \& Rossion, B. (2005). The face-sensitive N170 and VPP components manifest the same brain processes: The effect of reference electrode site. Clinical Neurophysiology, 116(11), 2613-2631. http://dx.doi.org/10.1016/j.clinph.2005.07.005

Kirouac, G., \& Doré, F. Y. (1984). Judgment of facial expressions of emotion as a function of exposure time. Perceptual and Motor Skills, 59, 147-150. Retrieved from http://www.ncbi.nlm.nih.gov/pubmed/6493929

Lang, P. J., Bradley, M. M., \& Cuthbert, B. N. (1997). International affective picture system (IAPS): Technical manual and affective ratings. University of Florida, Gainesville, FL.

LeDoux, J. E. (1996). The Emotional Brain. New York. Simon \& Schuster.

Lindström, B. R., \& Bohlin, G. (2012). Threat-relevance impairs executive functions: Negative impact on working memory and response inhibition. Emotion, 12(2), 384-393. http://dx.doi.org/10.1037/a0027305

Liotti, M., Pliszka, S. R., Perez, R., Kothmann, D., \& Woldorff, M. G. (2005). Abnormal brain activity related to performance monitoring and error detection in children with ADHD. Cortex, 41, 377-388. Retrieved from http://www.ncbi.nlm.nih.gov/pubmed/15871602

Luo, W., Feng, W., He, W., Wang, N. Y., \& Luo, Y. J. (2010). Three stages of facial expression processing: ERP study with rapid serial visual presentation. NeuroImage, 49, 1857-1867. http://dx.doi.org/10.1016/j.neuroimage.2009.09.018

Mikhailova, E. S., \& Bogomolova, I. V. (2000). Evoked cerebral cortex activity in the human brain in conditions of the active and passive perception of facial expressions. Neuroscience Behavioral Physiology, 30(6), 679-85. http://dx.doi.org/10.1023/A:1026650816978

Ochsner, K. N., \& Gross, J. J. (2005). The cognitive control of emotion. Trends in Cognitive Sciences, 9, 242-249. http://dx.doi.org/10.1016/j.tics.2005.03.010 
Pessoa, L. (2009). How do emotion and motivation direct executive control? Trends in Cognitive Science, 13, 160-166. http://dx.doi.org/10.1016/j.tics.2009.01.006

Pessoa, L., Padmala, S., Kenzer, A., \& Bauer, A. (2012). Interactions between cognition and emotion during response inhibition. Emotion, 12(1), 192-197. http://dx.doi.org/10.1037/a0024109

Phelps, E. (2006). Emotion and cognition: Insights from studies of the human amygdala. Annual Reviews of Psychology, 57, 27-53. http://dx.doi.org/10.1146/annurev.psych.56.091103.070234

Pinkham, A. E., Griffin, M., Baron, R. Sasson, N. J., \& Gur, R. C. (2010). The Face in the Crowd Effect: Anger superiority when using real faces and multiple identities. Emotion, 10(1), 141-146. http://dx.doi.org/10.1037/a0017387

Polich, J. (2007). Updating P300: An Integrative Theory of P3a and P3b. Clinical Neurophysiology, 118(10), 2128-2148. http://dx.doi.org/10.1016/j.clinph.2007.04.019

Pourtois, G., Schettino, A., \& Vuilleumier, P. (In press). Brain mechanisms for emotional influences on perception and attention: what is magic and what is not. Biological Psychology. http://dx.doi.org/10.1016/j.biopsycho.2012.02.007

Ro, T., Russell, C., \& Lavie, N. (2001). Changing faces: A detection advantage in the flicker paradigm. Psychological Science, 12, 94-99. http://dx.doi.org/10.1186/1471-2202-7-44

Rossion, B., Delvenne, J. F., Debatisse, D., Goffaux, V., Bruyer, R., Crommelinck, M., \& Guerit, J. M. (1999). Spatio-temporal localization of the face inversion effect: an event-related potentials study. Biological Psychology, 50(3), 173-189. http://dx.doi.org/10.1016/S0301-0511(99)00013-7

Sakaki, M., \& Niki, K. (2011). Effects of the brief viewing of emotional stimuli on understanding of insight solutions. Cognitive, Affective \& Behavioral Neuroscience, 11, 526-540. http://dx.doi.org/10.3758/s13415-011-0051-0

Sakaki, M., Niki, K., \& Mather, M. (2012). Beyond arousal and valence: The importance of the biological versus social relevance of emotional stimuli. Cognitive, Affective \& Behavioral Neuroscience, 12, 115-139. http://dx.doi.org/10.3758/s13415-011-0062-x

Schmajuk, M., Liotti, M., Busse, L., \& Woldorff, M. G. (2006). Electrophysiological activity underlying inhibitory control processes in normal adults. Neuropsychologia, 44, 384-395. http://dx.doi.org/10.1016/j.neuropsychologia.2005.06.005.

Schulz, K. P., Fan, J., Magidina, O., Marks, D. J, Hahn, B, \& Halperin, J. M. (2007). Does the emotional go/no-go task really measure behavioral inhibition? Convergence with measures on a non-emotional analog. Archieves of Clinical Neuropsychology, 22, 151-160. http://dx.doi.org/10.1016/j.acn.2006.12.001

Schulz, K. P., Clerkin, S. M., Halperin, J. M., Newcorn, J. H., Tang, C. H. Y., \& Fan, J. (2009). Dissociable neural effects of stimulus valence and preceding context during the inhibition of responses to emotional faces. Human Brain Mapping, 30(9), 2821-2833. http://dx.doi.org/10.1002/hbm.20706

Shafritz, K. M., Collins, S. H., \& Blumberg H. P. (2006). The interaction of emotional and cognitive neural systems in emotionally guided response inhibition. NeuroImage, 31, 468-475. http://dx.doi.org/10.1016/j.neuroimage.2005.11.053

Smith, J. L., Johnstone, S. J., \& Barry, R. J. (2008). Movement-related potentials in the Go/NoGo task: The P3 reflects both cognitive and motor inhibition. Clinical Neurophysiology, 119, 704-714. http://dx.doi.org/10.1016/j.clinph.2007.11.042

Schupp, H. T., Öhman, A., Junghöfer, M., Weike, A. I., Stockburger, J., \& Hamm, A. O. (2004). The facilitated processing of threatening faces: An ERP analysis. Emotion, 4(2), 189-200. http://dx.doi.org/10.1037/1528-3542.4.2.189

Steidl, S., Razik, F., \& Anderson, A. K. (2011). Emotion enhanced retention of cognitive skill learning. Emotion, 11(1), 12-19. http://dx.doi.org/10.1037/a0020288

Tipples, J., \& Sharma, D. (2000). Orienting to exogenous cues and attentional bias to affective pictures reflect separate processes. British Journal of Psychology, 91, 87-97. http://dx.doi.org/10.1348/000712600161691

Vanderhasselt, M. A., Kühn, S., \& De Raedt, R. (2011). Healthy brooders employ more attentional resources when disengaging from the negative: an event-related fMRI study. Cognitive, Affective, \& Behavioral Neuroscience, 11, 207-216. http://dx.doi.org/10.3758/s13415-011-0022-5 
Vanlessen, N., \& Rossi, V., De Raedt, R., \& Pourtois, G. (2013). Positive emotion broadens attention focus through decreased position-specific spatial encoding in early visual cortex: Evidence from ERPs. Cognitive, Affective, \& Behavioral Neuroscience, 13, 60-79. http://dx.doi.org/10.3758/s13415-012-0130-x

Verbruggen, F., \& De Houwer, J. (2007). Do emotional stimuli interfere with response inhibition? Evidence from the stop signal paradigm. Cognition \& Emotion, 21(2), 391-403. http://dx.doi.org/10.1080/02699930600625081

Vuilleumier, P., Armony, J. L., Driver, J., \& Dolan, R. J. (2001). Effects of attention and emotion on face processing in the human brain: An event-related fMRI study. Neuron, 30, 829-841. http://dx.doi.org/10.1016/S0896-6273(01)00328-2

Westerhausen, R., Moosmann, M., Alho, K., Belsby, S. O., Hämäläinen, H., Medvedev, S., Specht, K., \& Hugdahl, K. (2010). Identification of attention and cognitive control networks in a parametric auditory fMRI study. Neuropsychologia, 48, 2075-2081. http://dx.doi.org/10.1016/j.neuropsychologia.2010.03.028

Williams, L. M., Palmer, D., Liddell, B. J., Song, L., \& Gordon, E. (2006). The when and where of perceiving signals of threat versus non-threat. NeuroImage, 31, 458-467. http://dx.doi.org/10.1016/j.neuroimage.2005.12.009

Yu, F., Yuan, J., \& Luo, Y. (2009). Auditory-induced emotion modulates processes of response inhibition: An event-related potential study. NeuroReport, 20, 25-30. http://dx.doi.org/10.1097/WNR.0b013e32831ac9b1

Yuan, Y., Guan, G., Hong, G., \& Yi-Hong, Q. (2011). Early event-related potential components in face perception reflect the sequential neural activities. Acta Physiologica Sinica, 63(2), 97-105. Retrieved from http://www.actaps.com.cn/qikan/manage/wenzhang/2011-2-01.pdf

Zhang, W., \& Lu, J. (2012). Time course of automatic emotion regulation during a facial Go/Nogo task. Biological Psychology, 89(2), 444-449. http://dx.doi.org/10.1016/j.biopsycho.2011.12.011 